\title{
Setting Mental Health Priorities in Ghana: A 15-Year Contextual Analysis of the Presidential State of the Nation Address
}

\author{
Emmanuel Nii-Boye Quarshie ${ }^{1, *(\mathbb{D})}$, Priscilla Ayebea Davies ${ }^{2}$ and Pearl Ama Otoo ${ }^{3,+}$ \\ 1 Department of Psychology, University of Ghana, Legon, Accra P.O. Box LG 84, Ghana \\ 2 Office of the Vice Chancellor, Pentecost University, Sowutuom Campus, Kaneshie, \\ Accra P.O. Box KN 1739, Ghana; padavies@pentvars.edu.gh \\ 3 Department of Statistics, University of Ghana, Legon, Accra P.O. LG 115, Ghana \\ * Correspondence: enquarshie@ug.edu.gh or enquarshie@gmail.com \\ + Deceased.
}

\section{check for}

updates

Citation: Quarshie, E.N.-B.; Davies, P.A.; Otoo, P.A. Setting Mental Health Priorities in Ghana: A 15-Year

Contextual Analysis of the

Presidential State of the Nation

Address. Challenges 2021, 12, 22.

https://doi.org/10.3390/

challe12020022

Academic Editors

Palmiro Poltronieri and Susan

L. Prescott

Received: 29 July 2021

Accepted: 8 September 2021

Published: 10 September 2021

Publisher's Note: MDPI stays neutral with regard to jurisdictional claims in published maps and institutional affiliations.

Copyright: (c) 2021 by the authors. Licensee MDPI, Basel, Switzerland. This article is an open access article distributed under the terms and conditions of the Creative Commons Attribution (CC BY) license (https:/ / creativecommons.org/licenses/by/ $4.0 /$ )

\begin{abstract}
Globally, mental health issues have been neglected and allowed to be suppressed by stigma and discrimination for a very long time, although mental disorders are responsible for about $30 \%$ of the global non-fatal disease burden. Thus, the global call for solution to this challenge admonishes governments, donors, and mental health service users to prioritise mental health. Towards this end, speeches by key political actors can be used to garner public support and set out strong arguments for the prioritisation of mental health. Guided by the agenda-setting theory, this study sought to contribute to the evidence on the mental health priorities in Ghana by conducting a summative qualitative content analysis of the state of the nation addresses (SONAs) presented by presidents of Ghana from 2007 to 2021. Findings show that no mental health condition was highlighted in any of the SONAs, and mental health priorities in terms of policy and investment were superficial, inadequate, and woefully incomparable to those of physical health. It is suggested that government should heighten mental health priorities, given that mental disorders are leading the top 10 causes of the years lived with disability burden in the country.
\end{abstract}

Keywords: Ghana; mental health; mental health priorities; state of the nation address

\section{Introduction}

Mental health refers to "a state of well-being in which every individual realizes his or her own potential, can cope with the normal stresses of life, can work productively and fruitfully, and is able to make a contribution to her or his community" [1]. Globally, mental health issues have been neglected and allowed to be suppressed by stigma and discrimination for a very long time [2-4], although mental disorders are responsible for about $30 \%$ of the global nonfatal disease burden and $10 \%$ of the total global disease burden $[4,5]$. On the effects of mental disorders, the WHO observes that "the magnitude, suffering and burden in terms of disability and costs for individuals, families and societies are staggering" [2]. In terms of mental health, all nations can be thought of as developing [6]; however, compared to high-income countries, the burden of mental health challenges is higher in African and other low- and middle-income countries (LAMICs) [3,5,7-9]. Ironically, the concern and investment priorities of LAMICs for physical health are comparatively and consistently higher than for mental health [5,8,9]. Against this backdrop, the WHO $[2,10,11]$ and key global mental health researchers and stakeholders [3,4,9] have strongly advocated a review of this imbalanced trend in order to scale up mental healthcare, as there can be "no health without mental health" [5]. Thus, the global clarion call for a solution to this challenge admonishes governments, donors, and mental health service users of countries to prioritise mental health by increasing investment in mental health care through the establishment of specifically targeted policies, plans, and initiatives to promote and support mental health [6]. 
Towards the goal of formulating targeted health policies, speeches by key political actors can be used to garner public support and set out strong arguments for the prioritisation of mental health [12]. Emerging evidence suggests that health-related beliefs and attitudes and health behaviours of citizens are likely influenced by key political actors speeches and calls to be part of a collective action or inaction $[13,14]$. For example, in the midst of the current COVID-19 pandemic, there are research findings to suggest that the chronology, context, and contents of public speeches by heads of governments and presidents around the world are having a powerful influence on their citizens' adherence to preventive protocols and containment restrictions [13-16]. Even though rarely used, some recent studies have identified and analysed periodic speeches by key political actors as a lens for peering into the policy response and priorities related to, for example, public health, social welfare, nationalism, and tourism [14-18].

Therefore, the current study seeks to extend the evidence on Ghana's mental health priorities through the examination of the state of the nation addresses (SONAs) delivered by presidents of the country during the past 15 years (i.e., 2007-2021). Additionally, it is hoped that evidence gathered from this study will help inform various advocacy programmes and stakeholder activities aimed at calling on the government of Ghana to prioritise mental health in the country.

Mental health in Ghana: Ghana is a West African country with an estimated population of 30.9 million [19]. About $71.2 \%$ of Ghanaians identify as Christians, $17.6 \%$ as Muslims, 5.2\% as African Traditional Religion adherents, and 5.3\% without any religious affiliation [20]. Ghana is a lower-middle income country with a medium human development index (HDI rank of 138) and a life expectancy of 64.1 years [21,22]. In terms of the Sustainable Development Goals (SDGs), Ghana has an index score of $65.4 \%$, with a global ranking of 100 out of 166 countries [21]. Regarding Ghana's burden of disease, evidence shows that, although medical/physical health conditions (e.g., malaria, HIV / AIDS, etc.) constitute the leading causes of premature deaths, mental health conditions (e.g., depressive disorders) are in the lead for years lived with disability (YLDs) in the country [23]. For example, lower respiratory infections, malaria, HIV / AIDS, stroke, ischemic heart disease, protein-energy malnutrition, neonatal sepsis, road injuries, preterm birth complications, and neonatal encephalopathy are the top 10 causes of premature deaths in Ghana [24]. The top 10 leading causes of years lived with disability have been identified as depressive disorders, lower back and neck pain, iron-deficiency anaemia, sense organ diseases, and skin diseases [24]. Notably, it has been observed that, comparatively, "depression continues to be a major contributor to Ghana's burden of disabling conditions and was responsible for three times more YLDs in 2013 than malaria" [24]. Evidence-based comprehensive analysis and discussion of the mental health system of Ghana-in terms of history, profile, policies, illness burden, and current status-have been offered elsewhere [25-29].

Ghana has the most comprehensive mental health legislation within West Africa [30-32]; however, the country's mental health system faces many severe challenges, including infrastructural constraints, acute human resource (workforce) shortage, social services challenges, organisational, legal and judicial, research and information system and financial challenges, as well as considerable institutionalised stigma $[28,29,32,33]$. In terms of access to mental healthcare by the public, only $2.8 \%$ of mentally ill persons are able to access treatment, with most mental health patients unable to receive professional care [29]. Relative to the WHO benchmark of one psychiatrist/100,000 population, Ghana's psychiatrist to population ratio is 0.058 per 100,000 population, and 0.065 psychologists per 100,000 population [34]. Ghana's psychiatrist/population ratio is comparable to what exists in neighbouring Togo $(0.054 / 100,000)$, Burkina Faso $(0.039 / 100,000)$, and Ivory Coast $(0.130 / 100,000)$, even though all are less than enough [34].

Currently, mental healthcare and allied care activities in Ghana are regulated by the Mental Health Act, which was passed in 2012 [27,31,32]. The key evidence is that, compared to the physical/medical health sub-sector, the mental health sub-sector of the 
country remains under-served and under-resourced, and continues to be less prioritised on the national development agenda by government $[25,27,29,32]$.

State of the nation address (SONA): Article 67 of the 1992 Constitution of Ghana stipulates that "the President shall, at the beginning of each session of Parliament and before a dissolution of Parliament, deliver to Parliament a message on the state of the nation". In pursuance of this, the president of Ghana, usually in the month of February every year, presents to Parliament an address on the state of the nation. The state of the nation address (SONA) affords the president a platform to report important issues (challenges and successes) in the past year and to outline key areas of investment, development, and policy priority for the ensuing year. Thus, although partly considered a stock-taking exercise and celebratory, the SONA is also considered as an agenda-setting activity and an address of prioritisation, as it identifies areas of immediate commitment of an incumbent government [35]. There is usually a live broadcast of the event on radio and television networks across the country. Although the content of the SONA may vary based on the exigencies of the time and the political vision, ideologies, and philosophy of the political party in government, usually, the SONA is organised around some recurrent thematic areas of national life. These include (but are not exclusive to) governance, education, health, social protection, youth and sports, the economy (trade and commerce), infrastructural growth, and housing. Data for the current study were mainly drawn from the 'health' thematic sections of the SONAs presented from 2007 to 2021. These SONAs were presented by four different presidents (all males) to the Parliament of Ghana.

Theoretical framework: This study adopts the agenda-setting theory of mass communication of public agenda/issues in news [36] to explicate and interpret the observations made. Basically, the agenda-setting theory proposes that "the prominence of elements in the news influences the prominence of those elements among the public" [36,37]. In other words, the salience of the issues on the news agenda in turn influences their salience on the public agenda. The process of the influence starts with the issues receiving higher attention in the mass media [37]. Agenda-setting, thus, heightens the relevance and importance of issues (given prominence in mass media communication) in the minds of the public [38]. It presupposes that, for example, if, in a public communication of government policy, a politician draws prominent attention to certain aspects of the issues considered relevant to government policies at the expense of others, the aspects of the issues given prominence and made salient in the communication are more likely to influence the understanding, interpretation, opinions, and attitudes of not only the listening public towards the issues, but also the development agenda and policies of the government [39-41].

In the context of this study, it is assumed (based on the agenda-setting theory) that the health issues (e.g., diseases, infrastructure, workforce, insurance, etc.) given prominence in the state of the nation address are more likely to be featured in the immediate government development priorities, but those health issues given a glimpse of or no attention in the SONAs are less (or not) likely to be featured in the immediate government development commitment and investment priorities for the ensuing year.

\section{Materials and Methods}

This is a qualitative study that drew data from the SONAs delivered by presidents of Ghana during the previous 15 years (i.e., 2007-2021). Two authors (E.N.B.Q. and P.A.D.) performed electronic searches of the "State of the Nation Addresses \& Budget Statements" repository on the official websites of the Parliament of Ghana (www.parliament.gh (accessed on 2 March 2021)) to access copies of the SONAs presented by presidents of Ghana from 2007 to 2021. In total, 15 SONAs were retrieved, each in a portable document format (PDF). The SONA is written and presented in English, the official language of Ghana.

Analysis: The 15 SONAs drawn were subjected to summative qualitative content analysis [42]. The summative approach to qualitative content analysis involves counting of the appearance of a particular word or content in textual material (manifest content analysis) and the discovery and interpretation of the underlying meanings (latent content 
analysis) of the words or the content [42]. Guided by the aim of this study and the sevenstep approach to conducting qualitative content analysis by Hsieh and Shannon [42], the thematic sections on health contained in the selected SONAs were iteratively searched for mental and medical/physical health conditions explicitly mentioned (and the number of times they occurred) across the entire corpus of the SONAs. Microsoft Excel (version 2013) was used to calculate and present the frequencies and percentages of the counts of the various health conditions identified in the SONAs. The unit of analysis was the SONA: the total number of times a term occurred in one SONA was considered as a count of occurrence. For example, if a health condition occurred (once or more) in a given SONA, the total number of occurrences of that health condition in that SONA was considered as one (i.e., a single count). Thus, the maximum number of counts for each term identified was 15 , according to the total number of SONAs $(n=15)$. The SONAs were iteratively read closely to identify and tease out the areas of national health that were highlighted as important for immediate investment and policy concern to the government. Relevant and compelling excerpts of the SONAs were culled verbatim to support the explication and interpretation of the selected categories.

\section{Results}

The findings were organised around two main themes: health conditions and disease burden, and areas of investment and policy direction.

Health conditions and disease burden: This theme relates to the various diseases and health conditions identified in the SONAs as worth focusing government attention and resources on. Across the period, no mental health condition was highlighted in any of the SONAs analysed. However, physical/medical health conditions were explicitly mentioned across the 15 SONAs analysed (see Table 1). For instance, communicable diseases (e.g., HIV / AIDS), non-communicable diseases (e.g., cancer and chronic respiratory disease), fevers (e.g., malaria fever and Ebola fever), and maternal and child health were explicitly highlighted.

Table 1. Occurrence of health conditions and disease burden in SONAs.

\begin{tabular}{ccc}
\hline Condition & Frequency & Percentage (\%) \\
\hline Mental Health & 0 & 0 \\
Physical Health: & 8 & 53.3 \\
Communicable diseases & 6 & 40.0 \\
Non-communicable diseases & 6 & 40.0 \\
Maternal and child health & 4 & 26.6 \\
Fevers & 2 & 13.3 \\
COVID-19 & &
\end{tabular}

On highlighting the past successes achieved by government in tackling the disease burden of the country, the 2016 SONA stated, for example, as follows:

"Mr. Speaker,... We have been successful in reducing annual AIDS deaths by $43 \%$. Through collaborative efforts to eliminate Mother-to-Child Transmission of HIV with advocacy at the highest level, we have achieved over $50 \%$ reduction of transmission of HIV from mother-to-child.... The Ghana AIDS Commission and its stakeholders have agreed on priorities for the new National Strategic Plan 2016-2020 towards achieving the 90-90-90 fast-track targets for Ghana (90\% of people living with HIV [PLHIV] know their status, 90\% of PLHIV on Antiretroviral treatment and 90\% achieve immune suppression)" (SONA, 2016, p. 11).

The above quote indicates a very deep commitment of government to tackling HIV/AIDS but also shows the resolution of government to harness every means possible towards achieving a 90\% reduction in the problem of HIV / AIDS. Again, the 2011 SONA set an agenda of total elimination of mother-to-child HIV transmission within the following five years [43]; the 2013 SONA reported that government had invested 150 
million Ghanaian Cedis to support the implementation of this strategic plan [44]; the 2014 SONA promised continuous targeted public awareness campaigns and stigma reduction efforts and funds mobilisation for scaling up antiretroviral therapy programmes [45]; and the 2015 and 2016 SONAs reported the expansion of domestic supply of antiretroviral drugs through government's collaboration with local pharmaceutical companies [46], and the disbursement of 50 million Ghanaian Cedis to these companies to achieve uninterrupted supply of antiretroviral drugs for HIV / AIDS patients in Ghana [47].

Similarly, regarding non-communicable diseases (NCDs), the SONA stated that:

"Mr. Speaker, ... We are poised to invest heavily in the coming years in education and preventive healthcare for the treatment of chronic diseases due to lifestyle choices- diseases such as Hypertension, Diabetes, High Blood Cholesterol, and Obesity. The investment in preventive health is even more prudent as our nutritional habits continue to change." (SONA, 2016, p. 7).

The excerpt above shows the enthusiasm of government towards heavy investments into the prevention and control of NCDs in the country. Regarding maternal and child health, although the government of Ghana introduced a nation-wide coverage fee-free delivery care in 2005, subsequent SONAs (e.g., in 2008 and 2009) were used to set the agenda of continuous pursuance of the free maternal care policy and de-linking children from their parents in the National Health Insurance Scheme membership database. There is evidence to suggest that the implementation of this free delivery care was well received by pregnant women (particularly, from low socio-economic backgrounds and resource-poor communities) across the country; the policy led to beneficial effects of motivating pregnant women to seek early antenatal care, which led to early detection and better management of (potential) complications [48]. While these are laudable ideas and plans of action, they appear skewed in favour of physical/medical health, to the neglect of mental health. The paradox in this regard is related to the modest cost of financing mental health care in LAMICs, including Ghana. The WHO observes that the financial resources required are relatively modest, especially in low- and middle-income countries; yet, governments of such countries have less investment priorities for mental health. For instance, in lowincome countries, US\$2 per capita is needed annually, whereas lower middle-income countries require US\$3-4 [49,50].

Areas of investment and policy direction: This theme covers the various areas of national health identified in the SONAs as immediate priority areas where budgetary allocation and policy efforts would be focused by government in the ensuing year, and presumably, within the foreseeable medium to long term. Broadly, the SONAs scantly highlighted three areas related to mental health (i.e., legislation, workforce, and infrastructure); however, six areas related to physical/medical health were highlighted as priority areas for investment by government (see Table 2).

Table 2. Areas of health investment and policy direction for the ensuing year.

\begin{tabular}{ccc}
\hline Area & Frequency & Percentage (\%) \\
\hline Mental Health: Legislation & 2 & 13.3 \\
Mental health facility & 1 & 6.6 \\
Workforce & 1 & 6.6 \\
Physical Health: National Health Insurance Scheme & 12 & 80.0 \\
Medical facility and infrastructure & 10 & 66.6 \\
Workforce & 6 & 40.0 \\
Public health promotion & 6 & 40.0 \\
Pharmaceuticals & 4 & 26.6 \\
Ambulance and emergency services & 5 & 33.3 \\
\hline
\end{tabular}

Government policy priority for mental health occurred four times across the 15 SONAs: two times in respect of legislation, (SONA, 2011 and 2013), and one each in respect of workforce (SONA, 2013) and Infrastructure or facility (SONA, 2021). On legislation, the focus 
was on the formulation and implementation of a legislative framework to guide mental healthcare activities in the country. It was highlighted thus:

"Madam Speaker, following the passage of the Mental Health Act, Government will adopt a community mental health care strategy to facilitate the implementation of the Act. The required Legislative Instrument to operationalize other aspects of the Act will also be laid before Parliament." (SONA, 2011, p. 13).

Formal mental healthcare activities in Ghana began in 1888 with the passage of the Lunatic Asylum Ordinance, which was replaced in 1972 by the National Redemption Council Decree (NRCD 30) [25]. Apart from its inadequacy in addressing basic human right issues in the institutional care of mental health patients, the NRCD 30 was not implemented during the over 40 years of its existence $[25,27]$. Several attempts made during the 1990s (i.e., 1992, 1996, and 2000) to push for a revision of the NRCD 30 were unsuccessful, until 2004, when a new Mental Health Bill, drafted with the technical assistance of the World health Organisation, was presented to Ghana's Parliament for consideration [25]. Finally, the Mental Health Bill (now the Mental Health Act) was passed by the Parliament of Ghana into law in March 2012, after over eight years of deliberations and consultations [27,31,51]. The assertion quoted above (i.e., SONA, 2011, p. 13) was made approximately a year to the passage of the Mental Health Act in 2012. Further, the quote was the first assertion and promise made in relation to mental health legislation and implementation across all the 15 SONAs analysed. In 2013, the year following the passage of the Mental Health Act, the SONA focused on the implementation of the Act 2012: "Mr. Speaker, ... We will pursue the implementation of the Mental Health Act in order to mainstream psychiatric treatment and care for our population" (SONA, 2013, p. 4). The coda of this quote (i.e., " . . in order to mainstream psychiatric treatment and care ... ") plausibly implies that, hitherto, mental health care services in the country had been left to the fringes and treated (if at all) as a peripheral health issue. It further means that mental health had been subordinated to medical/physical health issues in the health polices constituted and implemented by government over the years. However, it is worthy of note that subsequent SONAs, from 2014 to 2020, did not explicitly mention or highlight anything in relation to mental health.

To ensure meaningful pursuance and implementation of the Mental Health Act 2012, government must first and foremost empower and resource the key legitimate institution (i.e., the Mental Health Authority), which is primarily mandated to exercise an oversight responsibility regarding the implementation of the Mental Health Act [27,31]. Government must ensure that the Mental Health Authority, together with other similar primary stakeholder institutions, is adequately resourced to enable them carry out their mandate in the country. Unfortunately, five years after the promise by government in 2013 (see foregoing quote from SONA, 2013, p. 4), the Chief Executive Officer of the Mental Health Authority has reported that "there is little or no money from the government to enable us [the Mental Health Authority] to run mental health activities" [52]. It is also troubling to note that, to date, the Legislative Instrument that will operationalise critical aspects of the Mental Health Act, including setting up the mechanism of funding mental healthcare in the country, has still not been passed-although the Legislative Instrument has been presented to Parliament and its passage was promised in the 2011 SONA [31,52,53].

This revelation is indicative of the lack of (adequate) support by government to the mental health sub-sector of the nation's health. It is also consistent with earlier evidence that, generally, the budget of the Ministry of Health of Ghana, for the three psychiatric hospitals in the country, has been described as "ring-fenced", in that the de facto funding of mental health by government is usually far less than required to meet the needs of the institutions [29,53].

Regarding government's plan to address the workforce deficit of the health sector of the country the following plans were highlighted in the 2013 SONA:

"Mr. Speaker, with regard to the deficit in health personnel, we will consolidate the gains made in the training of health care professionals through the establishment of the Univer- 
sity of Allied and Health Sciences by transforming the Kintampo Rural Health Training Institute into a University College to support the training of Physician Assistants for our ambulance and emergency services as well as the training and deployment of clinical psychologists and environmental Health Inspectors." (SONA, 2013, p. 4).

The plan outlined in the above excerpt to expand the workforce base for the health sector appears laudable and potentially beneficial, if followed through. The plan to train and deploy clinical psychologists is particularly important, given that for a country of over 30 million people there are only 94 clinical psychologists, who are largely employed in academic institutions [54]. However, in the following year, 2014, the SONA reported thus:

"Mr. Speaker, ... More Nursing and Midwifery Training and Medical Assistants Training Institutions are being opened... So far, more than 3000 medical personnel have been trained. These include, medical assistants, midwives, public and community health nurses." (SONA, 2014, p. 7).

The excerpt above reports of 3000 newly trained medical personnel. It does not explicitly mention in the said list of trained personnel any mental health professional, although the promise (see earlier quote SONA, 2013, p. 4) was to train personnel to meet the workforce needs of the health sector (presumably including mental health).

Regarding facility and infrastructural expansion within the health sector, it was reported in the 2016 SONA thus:

"Mr. Speaker, ... Work on the following hospitals is also progressing: 250-bed Regional Hospital in Kumasi-Sewua; 60-bed District Hospital in Salaga; 60-bed District Hospital in Tepa; 60-bed District Hospital in Nsawkaw; 60-bed District Hospital in KonongoOdumasi; 100-bed Municipal Hospital in Atomic-Accra. Rehabilitation of the 295-bed Bolgatanga Hospital is progressing satisfactorily. Work on a new modern Emergency Department for the Korle-bu Teaching Hospital is $90 \%$ completed. A 12-bed intensive care unit (ICU) for the department of surgery has been refurbished and equipped." (SONA, 2016, p. 9).

Although these are commendable efforts by the government to improve and expand the infrastructural needs of medical hospitals, it is expected that similar efforts will be directed at improving the status of mental hospitals and community rehabilitative care centres across the country. Thus far, there are only three mental hospitals in the country (namely, the Accra, Ankaful, and Pantang psychiatric hospitals), which are hugely underresourced, overstretched, and severely congested [29]. Of these three mental hospitals, two are located in Accra alone, the national capital in the south, and one is located in the Central Region of the country, also in the south. In all, there are 1322 beds within the three hospitals and 123 mental health outpatient care services across the country [29]. Thus, apart from being incapable of serving the over 30 million people across the country, all three mental hospitals are located in urban areas within two southern regions, with none located in a rural community nor in any of the 14 other regions of the country. The congestion and pressure on these three mental hospitals are severe to the extent that it is not uncommon to find people experiencing severe forms of mental illness roaming the streets of cities and towns, and others living as homeless persons occupying public spaces in villages and peri-urban areas (some authors have described them loosely as 'vagrant psychotics') $[55,56]$. Recent media reports show that some of these mental patients have become vulnerable to public (physical) attacks, and in other instances, some are killed by family members or community members without any provocation [56,57].

Notably, however, it is reassuring to acknowledge that in the most recent SONA, the president announced a new agenda (Agenda 111) to construct 100-bed District Hospitals in the 101 districts that have no hospitals, seven Regional Hospitals, two new psychiatric hospitals, one each for the Middle Belt and Northern Belt, and to rehabilitate the EffiaNkwanta Hospital in the Western Region. The president observed that "Agenda 111 is part of a massive vision for Ghana's healthcare sector, the realisation of which will lead to Ghana becoming a Centre of Medical Excellence and a destination for medical tourism" (SONA, 2021, 
p. 4). It is still early days to doubt these promises; however, it is the authors' firm belief that if these promises are carried through, they will lead to some improvement in the status of the mental healthcare infrastructure in Ghana. During the period of interest of this study (2007-2021), the four presidents of Ghana have come from only two political parties. Within the lens of party politics and manifesto promises, it appears that presidents from both parties have been generally apathetic and less inclined to direct massive investment in mental healthcare, relative to medical care. However, it is hoped that the fulfilment of Agenda 111 could potentially enable Ghana to even commoditise psychiatric health care, at least, across the subregion. Thus far, only South Africa remains the major medical tourism destination within sub-Saharan Africa [58,59].

\section{Discussion}

Two key findings emerged from this study: (1) no mental health condition was explicitly mentioned in any of the 15 SONAs presented to Ghana's Parliament from 2007 through 2021, although several medical/physical health conditions were explicitly mentioned; and (2) government investment and policy implementation priorities for mental health across the study period could be described as superficial and woefully incomparable to those for medical/physical health.

The visible absence of any mental health condition in the 15 SONAs analysed in this study, although mental health conditions are in the lead of causes of years lived with disability of the country, is reflective of the general attitude, particularly, in LAMICs, where matters related to mental health are less important compared to physical health issues [6,8]. We agree with the position by Bolton: "When considering social and economic development, it is a mistake to regard major causes of disability as less important than the causes of mortality" [8]. The argument is that the commonplace of morbidity or disability makes it more important than mortality, in social and economic terms. In Ghana, the top 10 causes of premature death (which were given prominence across most of the 15 SONAs analysed in this study) are all medical/physical health conditions. Certainly, when people die, they neither contribute to nor use (the scarce) resources available to their families and societies; however, people with morbidity or disabilities — caused by mental health problems, e.g., depressive disordersmay become severely dysfunctional $[4,8]$, which implies that their resource contribution will be very much reduced or lost, and the family or society will have to spend the available scarce resources on them, lasting sometimes for years or decades. Again, it is now an established fact that mental health disorders are important risk factors for other diseases, intentional and unintentional injuries, and suicide $[3,4,6,11]$. In other words, mental disorders increase the chances of getting ill from other physical diseases, such as diabetes and cardiovascular diseases, and vice versa. Therefore, as observed by recent studies, in countries where programmes and policies related to health are focused on mortality issues without the same or equal focus on morbidity, the resultant effect could be a high prevalence and incidence of disability, which, in turn, may account for low economic development $[3,4,6,9]$.

In the light of the agenda-setting theory, it can be argued that medical/physical health concerns receive higher priorities by government, as physical health conditions are given higher prominence in the SONAs. However, the mental health priorities of the government of Ghana can be described as superficial in that no mental health condition was even mentioned in the SONAs, in spite of the fact that mental health conditions are leading the top 10 causes of the years lived with disability burden in the country. Thus, consistent with the existing evidence $[27,29]$, the findings of the current study could be pointing to the suggestion that mental health priorities in Ghana can be described as low, superficial, and woefully incomparable to that of physical health. This is owed to the general lack of political will and commitment, inadequate allocation of resources, institutionalised stigma of mental health issues, and general attitude of subordinating mental health issues to medical/physical health concerns. Thus, given that there can be no health without mental health, that the financial resources needed to boost mental health services are relatively 
modest, and that only $2.8 \%$ of Ghana's population is able to access mental health care, it has become imperative for the government of Ghana, donors, the private sector, and other key stakeholders and mental health service users to work together to give equal priority and investment attention to mental health in the country.

Although this study contributes to the evidence-base on mental priorities in Ghana, it may be limited in a way. The SONA, basically, highlights some important portions of the broader and much comprehensive medium-term development policy framework of the incumbent government. The implication is that the SONA is only a snapshot of the comprehensive medium-term development of the government.

\section{Conclusions}

In the current study, we applied a summative qualitative content analysis to 15 SONAs presented by the presidents of Ghana between 2007 and 2021. Findings suggested a conspicuous absence of any mental health condition in the SONAs analysed, while mental health policy priorities were low, superficial, and woefully incomparable to that of medical/physical health. Emerging evidence suggests that public speeches by heads of governments and presidents around the world are having a positive influence on their citizens' adherence to preventive protocols of the current COVID-19 pandemic. It is thus recommended that speeches by key political actors can be used to garner public support and set out strong arguments for the prioritisation of mental health, because there can be no health without mental health.

Author Contributions: Conceptualization, E.N.-B.Q. and P.A.D.; data curation, E.N.-B.Q., P.A.D. and P.A.O.; methodology, E.N.-B.Q., P.A.D. and P.A.O.; formal analysis, E.N.-B.Q., P.A.D. and P.A.O.; validation, E.N.-B.Q. and P.A.D.; writing—original draft preparation, E.N.-B.Q., P.A.D. and P.A.O.; writing-review and editing, E.N.-B.Q.; supervision, E.N.-B.Q. All authors have read and agreed to the published version of the manuscript.

Funding: This research received no external funding.

Institutional Review Board Statement: Not Applicable.

Informed Consent Statement: Not Applicable.

Data Availability Statement: Publicly available datasets were analysed in this study. These data can be found here: https: / / www.parliament.gh (accessed on 2 March 2021).

Dedication: This paper is dedicated to the loving memory of our colleague, Pearl Ama Otoo, who passed away while the manuscript was near submission to this journal; Ama's contribution to this work as invaluable.

Conflicts of Interest: The authors declare no conflict of interest.

\section{References}

1. WHO. Promoting Mental Health: Concepts, Emerging Evidence, Practice (Summary Report); World Health Organization: Geneva, Switzerland, 2004.

2. WHO. Investing in Mental Health; World Health Organization: Geneva, Switzerland, 2003.

3. Fleischmann, A.; Arensman, E.; Berman, A.; Carli, V.; De Leo, D.; Hadlaczky, G.; Howlader, S.; Vijayakumar, L.; Wasserman, D.; Saxena, S. Overview evidence on interventions for population suicide with an eye to identifying best-supported strategies for LMICs. Glob. Ment. Health 2016, 3, e5. [CrossRef]

4. Mnookin, S.; World Bank Group; World Health Organization. Out of the Shadows: Making Mental Health a Global Development Priority. Available online: https:/ /www.who.int/mental_health/advocacy/wb_background_paper.pdf?ua=1 (accessed on 9 March 2017).

5. Prince, M.; Patel, V.; Saxena, S.; Maj, M.; Maselko, J.; Phillips, M.R.; Rahman, A. No health without mental health. Lancet 2007, 370, 859-877. [CrossRef]

6. Patel, V.; Saxena, S.; Lund, C.; Thornicroft, G.; Baingana, F.; Bolton, P.; Chisholm, D.; Collins, P.Y.; Cooper, J.L.; Eaton, J. The Lancet Commission on global mental health and sustainable development. Lancet 2018, 392, 1553-1598. [CrossRef]

7. Jacob, K.; Sharan, P.; Mirza, I.; Garrido-Cumbrera, M.; Seedat, S.; Mari, J.J.; Sreenivas, V.; Saxena, S. Mental health systems in countries: Where are we now? Lancet 2007, 370, 1061-1077. [CrossRef]

8. Bolton, P.A. The unknown role of mental health in global development. Yale J. Biol. Med. 2014, 87, 241-249. [PubMed] 
9. Chisholm, D.; Sweeny, K.; Sheehan, P.; Rasmussen, B.; Smit, F.; Cuijpers, P.; Saxena, S. Scaling-up treatment of depression and anxiety: A global return on investment analysis. Lancet Psychiatry 2016, 3, 415-424. [CrossRef]

10. WHO. Mental Health: Facing the Challenges, Building Solutions; WHO Regional Office for Europe: Copenhagen, Denmark, 2005.

11. WHO. Preventing Suicide: A Global Imperative; WHO: Geneva, Switzerland, 2014.

12. Jenkins, R. How to convince politicians that mental health is a priority. World Psychiatry 2013, 12, 266-268. [CrossRef] [PubMed]

13. Antonakis, J.; d'Adda, G.; Weber, R.; Zehnder, C. Just words? Just speeches? On the economic value of charismatic leadership. NBER Rep. 2019, 4, 1-90.

14. Ajzenman, N.; Cavalcanti, T.; Da Mata, D. More than words: Leaders' speech and risky behavior during a pandemic. In Cambridge-INET Working Paper Series; Institute for New Economic Thinking, Faculty of Economics, University of Cambridge: Cambridge, UK, 2020; pp. 1-48.

15. Phanthaphoommee, N. The generic structure of the Thai Prime Minister's weekly address. Indones. J. Appl. Linguist. 2021, 11, 114-123. [CrossRef]

16. Dada, S.; Ashworth, H.C.; Bewa, M.J.; Dhatt, R. Words matter: Political and gender analysis of speeches made by heads of government during the COVID-19 pandemic. BMJ Glob. Health 2021, 6, e003910. [CrossRef]

17. Adu-Ampong, E.A. State of the nation address and tourism priorities in Ghana-A contextual analysis. Tour. Plan. Dev. 2017, 14, 135-138. [CrossRef]

18. Adebisi, Y.A.; Rabe, A.; Lucero-Prisno, D.E., III. Risk communication and community engagement strategies for COVID-19 in 13 African countries. Health Promot. Perspect. 2021, 11, 137-147. [CrossRef]

19. Ghana Statistical Service. Projected Population by Region and Sex, 2010, 2015-2020. Available online: https: / / www.statsghana. gov.gh/ (accessed on 14 March 2021).

20. Ghana Statistical Service. 2010 Population E Housing Census Report; Ghana Statistical Service (GSS): Accra, Ghana, 2013.

21. UNDP. Human Development Report 2020: The Next Frontier: Human Development and the Anthropocene; United Nations Development Programme (UNDP): New York, NY, USA, 2020.

22. The World Bank. World Bank Country and Lending Groups. Country Classification. Available online: https:/ / datahelpdesk. worldbank.org/knowledgebase/articles/906519-world-bank-country-and-lending-groups (accessed on 10 March 2021).

23. Sipsma, H.; Ofori-Atta, A.; Canavan, M.; Osei-Akoto, I.; Udry, C.; Bradley, E.H. Poor mental health in Ghana: Who is at risk? BMC Public Health 2013, 13, 1-9. [CrossRef]

24. Institute for Health Metrics and Evaluation. Ghana: Findings from the Global Burden of Disease Study. Available online: https: //www.thecommonwealth-healthhub.net/wp-content/uploads/2016/02/Ghana_CW_CountryProfile_Final_12_14_15.pdf (accessed on 5 March 2020).

25. Asare, J. Mental health profile of Ghana. Int. Psychiatry 2010, 7, 67-68. [CrossRef]

26. Awenva, A.; Read, U.; Ofori-Attah, A.; Doku, V.; Akpalu, B.; Osei, A.; Flisher, A. From mental health policy development in Ghana to implementation: What are the barriers? Afr. J. Psychiatry 2010, 13, 184-191.

27. Doku, V.; Wusu-Takyi, A.; Awakame, J. Implementing the Mental Health Act in Ghana: Any challenges ahead? Ghana Med. J. 2012, 46, 241-250.

28. Read, U.M.; Doku, V. Mental health research in Ghana: A literature review. Ghana Med. J. 2012, 46, $29-38$.

29. Roberts, M.; Mogan, C.; Asare, J.B. An overview of Ghana's mental health system: Results from an assessment using the World Health Organization's Assessment Instrument for Mental Health Systems (WHO-AIMS). Int. J. Ment. Health Syst. $2014,8,16$. [CrossRef]

30. Esan, O.; Abdumalik, J.; Eaton, J.; Kola, L.; Fadahunsi, W.; Gureje, O. Global mental health reforms: Mental health Care in Anglophone West Africa. Psychiatr. Serv. 2014, 65, 1084-1087. [CrossRef]

31. Walker, G.H.; Osei, A. Mental health law in Ghana. BJPsych Int. 2017, 14, 38-39. [CrossRef]

32. Walker, G. Ghana Mental Health Act 846 2012: A qualitative study of the challenges and priorities for implementation. Ghana Med. J. 2015, 49, 266-274. [CrossRef]

33. Jack, H.; Canavan, M.; Ofori-Atta, A.; Taylor, L.; Bradley, E. Recruitment and retention of mental health workers in Ghana. PLoS ONE 2013, 8, e57940. [CrossRef]

34. WHO. Global Health Observatory Data Repository: Human Resources Data by Country. Available online: https://apps.who.int/ gho/data/node.main.MHHR (accessed on 5 July 2021).

35. Akyeampong, E.; Hill, A.G.; Kleinman, A. The Culture of Mental Illness and Psychiatric Practice in Africa; Indiana University Press: Bloomington, Indiana, 2015.

36. McCombs, M.E.; Shaw, D.L. The agenda-setting function of mass media. Public Opin. Q. 1972, 36, 176-187. [CrossRef]

37. Carroll, C.E.; McCombs, M. Agenda-setting effects of business news on the public's images and opinions about major corporations. Corp. Reput. Rev. 2003, 6, 36-46. [CrossRef]

38. McQuail, D. Mass communication and the public interest: Towards a social theory for media structure and performance. In Communication Theory Today; Crowley, D., Mitchell, D., Eds.; Polity: Cambridge, UK, 1994; pp. 235-253.

39. Gelders, D.; Bouckaert, G.; Van Ruler, B. Communication management in the public sector: Consequences for public communication about policy intentions. Gov. Inf. Q. 2007, 24, 326-337. [CrossRef]

40. Gelders, D.; Brans, M. Arguments for and against communication about policy intentions. Int. Public Manag. J. 2007, 8, 154-167. 
41. Gelders, D.; Ihlen, Ø. Government communication about potential policies: Public relations, propaganda or both? Public Relat. Rev. 2010, 36, 59-62. [CrossRef]

42. Hsieh, H.-F.; Shannon, S.E. Three approaches to qualitative content analysis. Qual. Health Res. 2005, 15, 1277-1288. [CrossRef]

43. Department of Official Reports; Parliament House. State of the Nation Address: "Raising Ghana to the Next Level", by H.E. John Evans Atta Mills, President of the Republic of Ghana. Thursday, February 17, 2011; Department of Official Reports; Parliament House: Accra, Ghana, 2011.

44. Department of Official Reports; Parliament House. State of the Nation Address: "Opportunities for All", Delivered by H.E. John Dramani Mahama, President of the Republic of Ghana. Thursday, February 21, 2013; Department of Official Reports; Parliament House: Accra, Ghana, 2013.

45. Department of Official Reports; Parliament House. State of the Nation Address: Delivered by H.E. John Dramani Mahama, President of the Republic of Ghana. Tuesday, February 25, 2014; Department of Official Reports; Parliament House: Accra, Ghana, 2014.

46. Department of Official Reports; Parliament House. State of the Nation Address: Delivered by H.E. John Dramani Mahama, President of the Republic of Ghana. Thursday, February 26, 2015; Department of Official Reports; Parliament House: Accra, Ghana, 2015.

47. Department of Official Reports; Parliament House. State of the Nation Address Presented to Parliament by H.E. John Dramani Mahama, President of the Republic of Ghana. Thursday, February 25, 2016; Department of Official Reports; Parliament House: Accra, Ghana, 2016.

48. Witter, S.; Arhinful, D.K.; Kusi, A.; Zakariah-Akoto, S. The experience of Ghana in implementing a user fee exemption policy to provide free delivery care. Reprod. Health Matters 2007, 15, 61-71. [CrossRef]

49. WHO. Mental Health: Strengthening Our Response. Available online: https://www.who.int/news-room/fact-sheets/detail/ mental-health-strengthening-our-response (accessed on 9 December 2018).

50. WHO. Mental Health. Available online: https://www.who.int/news-room/facts-in-pictures/detail/mental-health\# (accessed on 8 January 2020).

51. Osei, A.O.; Roberts, M.; Crabb, J. The new Ghana mental health bill. Int. Psychiatry 2011, 8, 8-9. [CrossRef]

52. Osei, A. The Mental Health Act 846, Six Years on. Available online: https://www.graphic.com.gh/news/health/the-mentalhealth-act-846-six-years-on.html (accessed on 18 December 2019).

53. Owusu, A.Y.; Asante, K.T. Policy Brief. Mental Healthcare in Ghana: A Serious Setback to Sustainable Healthcare for Development; Institute of Statistical, Social and Economic Research (ISSER), University of Ghana: Accra, Ghana, 2020.

54. Quarshie, E.N.B.; Annor, F.; Tagoe, T.; Osei-Poku, E.; Andoh-Arthur, J. Psychologists in Ghana: Analysis of the standing register. New Voices Psychol. 2016, 12, 55-69.

55. De-Graft Aikins, A. Mental illness and destitution in Ghana: A social-psychological perspective. In The Culture of Mental Illness and Psychiatric Practice in Africa; Akyeampong, E., Hill, A.G., Kleinman, A., Eds.; Indiana University Press: Bloomington, Indiana, 2015; pp. 112-143.

56. Abekah-Carter, K.; Oti, G.O. Perspectives of community members on homeless people with mental illness in Nsawam, Ghana. Int. J. Soc. Psychiatry 2020. [CrossRef]

57. Human Rights Watch. "Like a Death Sentence". Abuses against Person with Mental Disorders in Ghana; Human Rights Watch: New York, NY, USA, 2012.

58. Connell, J. Medical tourism: Sea, sun, sand and surgery. Tour. Manag. 2006, 27, 1093-1100. [CrossRef]

59. Crush, J.; Chikanda, A. South-South medical tourism and the quest for health in Southern Africa. Soc. Sci. Med. 2015, 124, 313-320. [CrossRef] 